\title{
Low gut microbiota diversity in early infancy precedes asthma at school age
}

\author{
Thomas Abrahamsson, H.E. Jakobsson, A.F. Andersson, B. Bjorksten, L. Engstrand and
} Maria Jenmalm

\section{Linköping University Post Print}

N.B.: When citing this work, cite the original article.

Original Publication:

Thomas Abrahamsson, H.E. Jakobsson, A.F. Andersson, B. Bjorksten, L. Engstrand and Maria Jenmalm, Low gut microbiota diversity in early infancy precedes asthma at school age, 2014, Clinical and Experimental Allergy, (44), 6, 842-850.

http://dx.doi.org/10.1111/cea.12253

Copyright: Wiley: 12 months http://eu.wiley.com/WileyCDA/

Postprint available at: Linköping University Electronic Press http://urn.kb.se/resolve?urn=urn:nbn:se:liu:diva-109137 
Thomas R Abrahamsson, MD, PhD ${ }^{1}$

Hedvig E Jakobsson, PhD $^{2}$

Anders F Andersson, $\mathbf{P h D}^{3}$

Bengt Björkstén, $\mathrm{MD}, \mathrm{PhD}^{4}$

Lars Engstrand, $\mathrm{MD}, \mathbf{P h D}^{2,3}$

Maria C Jenmalm, $\mathbf{P h D}^{1,5}$

1. Department of Clinical and Experimental Medicine, Division of Pediatrics, Linköping University, Sweden

2. Department of Microbiology, Tumor and Cell Biology, Karolinska Institutet, Stockholm, Sweden

3. KTH Royal Institute of Technology, Science for Life Laboratory, School of Biotechnology, Division of Gene Technology, Stockholm, Sweden

4. Institute of Environmental Medicine, Karolinska Institutet, Stockholm, and School of Health and Medical Sciences, Örebro University Sweden

5. Department of Clinical and Experimental Medicine, Unit of Autoimmunity and Immune Regulation, Division of Clinical Immunology, Linköping University, Sweden 
Division of Paediatrics

Linköping University Hospital

27

SE-581 85 Linköping,Sweden

Phone: +46-(10)-1030000

Fax: +46-(13)-148265.

E-mail: thoab@telia.com 


\section{ABSTRACT}

Background: Low total diversity of the gut microbiota during the first year of life is associated with allergic diseases in infancy, but little is known how early microbial diversity is related to allergic disease later in school age.

Objective: To assess microbial diversity and characterize the dominant bacteria in stool during the first year of life in relation to the prevalence of different allergic diseases in school age, such as asthma, allergic rhinoconjunctivitis and eczema.

Methods: The microbial diversity and composition was analyzed with barcoded 16S rDNA 454 pyrosequencing in stool samples at one week, one month and 12 months of age in 47 infants which were subsequently assessed for allergic disease and skin prick test reactivity at seven years of age (ClinicalTrials.gov ID NCT01285830).

Results: Children developing asthma $(\mathrm{n}=8)$ had a lower diversity of the total microbiota than non-asthmatic children at one week $(p=0.04)$ and one month $(p=0.003)$ of age, whereas allergic rhinoconjuctivitis $(n=13)$, eczema $(n=12)$ and positive skin prick reactivity $(n=14)$ at seven years of age did not associate with the gut microbiota diversity. Neither was asthma associated with the microbiota composition later in infancy (at 12 months). Children having IgE-associated eczema in infancy and subsequently developing asthma had lower microbial diversity than those that did not. There were no significant differences, however, in relative abundance of bacterial phyla and genera between children with or without allergic disease.

Conclusion and Clinical relevance: Low total diversity of the gut microbiota during the first month of life was associated with asthma but not allergic rhinoconjunctivitis in children at seven years of age. Measures affecting microbial colonisation of the infant during the first month of life may impact asthma development in childhood. 
Abrahamsson

\section{$59 \quad$ Key words}

60 Asthma; allergic rhinoconjunctivitis; birth; children; diversity; hygiene hypothesis;

61 microbiota; molecular microbiology

62

63 


\section{Introduction}

A limited microbial exposure may underlie the increase of allergic diseases in affluent countries [1]. Recent reports indicate that a high diversity of the gut microbiota in infancy may be more important than the prevalence of specific bacterial taxa [2-4]. The suggested underlying rationale is that the gut immune system reacts to exposure to new bacterial antigens and repeated exposure would enhance the development of immune regulation. Although sharing several common features, the phenotype and the mechanisms underlying the different allergic diseases such as asthma, eczema and allergic rhinoconjunctivitis (ARC) are heterogeneous [5-7]. Also, the importance of and relationship with the intestinal microbiota may differ between the different diseases. Previously, low gut microbial diversity during the first month of life has been associated with subsequent eczema [2, 8-10] and sensitization $[2,3,8]$, but still there are no studies reporting low gut microbial diversity preceding asthma development. This is probably primarily due to the fact that most of the clinical follow-ups have been performed in infancy [2, 8-10], when allergic asthma and rhinoconjunctivitis still are uncommon. It might also be a consequence of methodology limitations. The microbial detection sensitivity of terminal restriction fragment length polymorphism (T-RFLP) [8, 10] and denaturing gradient gel electrophoresis (DGGE) [3, 9], which were employed in all studies except one [2], is low, since the median number of peaks/bands detected in these studies was much lower than the expected number of bacterial species. Recently, by employing high-throughput 16S rRNA gene sequencing, we could confirm that low gut microbial diversity during the first month of life was associated with subsequent sensitization and eczema at two years of age [2]. In contrast to previous studies, we could also show that the differences in diversity were attributed to a specific bacterial phylum, Bacteroidetes, and the bacterial genus Bacteroides. 
89 A follow-up of this cohort at seven years of age, when respiratory allergic diseases are as

90 common as eczema, gave us the opportunity to assess whether microbial diversity and the

91 relative abundance of dominant bacteria in stool during the first year of life are also

92 associated with development of asthma and allergic rhinoconjunctivitis, and if the importance

93 of the gut microbiota composition during the first month of life lasts until school age. We also

94 hypothesized that the importance of and relationship with the intestinal microbiota differ

95 between the different allergic manifestations.

96

97 
Subjects and sample collection

100 The children included in this study were part of a larger study in South Eastern Sweden

101 between 2001 and 2005, evaluating allergy prevention in infants with family history of

102 allergic disease until two years of age with the probiotic Lactobacillus reuteri ATCC 55730

103 [11]. In this study the infant received L. reuteri or placebo daily from day 1-3 until twelve

104 months of age. Children admitted to the neonatal ward during the first week of life were

105 excluded. Stool samples were collected from the infants at age 5-7 days and at one month and

106 twelve months of age. The samples were immediately frozen at $-20^{\circ} \mathrm{C}$ following collections

107 and later stored at $-70^{\circ} \mathrm{C}$. At two years of age, a follow-up with microbial analyses with

108 barcoded 16S rDNA 454-pyrosequencing was performed, relating microbial diversity in these

109 stool samples with the development of IgE-associated eczema during the first two years of

110 life [2]. All 20 infants with IgE-associated eczema and stool samples available from all three

111 sampling occasions were included in these analyses, and 28 infants without any allergic

112 manifestation were randomly selected as controls. In total 47 of these 48 children have now

113 completed the present seven-year follow-up. The child who dropped out did not have any

114 allergic manifestation at two years of age. Seventeen children belonged to the probiotic and

11530 to the placebo group in the original study. All infants were breastfed for at least one

116 month, and no infant received antibiotics before one month of age. A written informed

117 consent was obtained from both parents before inclusion. The Regional Ethics Committee for

118 Human Research at Linköping University approved the study (M171-07). The study is

119 registered at ClinicalTrials.gov (ID NCT01285830).

120

121 Clinical investigations 
122 A clinical follow-up was performed by research nurses at seven years of age ( \pm 3 months).

123 Before the visit, the parents completed a questionnaire based on the International Study of

124 Asthma and Allergies in Childhood (ISAAC) questionnaire for 6-7 year old children

125 (http://isaac.auckland.ac.nz/Index.html), supplemented with questions regarding

126 gastrointestinal symptoms, antibiotic and probiotic intake during the last month, family size,

127 pets and parental smoking. Data pertaining infancy was collected in the two-year follow-up

128 [11]. The visits included structured interviews related to symptoms of allergic disease,

129 physical examination, spirometry and measurement of fractional exhaled nitric oxid ( $\left.\mathrm{FE}_{\mathrm{NO}}\right)$.

130 Spirometry was performed with Jaeger Masterscope version 4.5 (Erich Jaeger GmbH,

131 Würzburg, Germany). Forced expiratory volume at 1 second $\left(\mathrm{FEV}_{1.0}\right)$, and the functional vital

132 capacity $(\mathrm{FVC})$ were assessed. The $\mathrm{FVC} \%$ was calculated from the ratio $\mathrm{FEV}_{1.0} / \mathrm{FVC}$. A

$133 \mathrm{FVC} \%<80 \%$ was regarded as pathological. Reversibility test with $\mathrm{FEV}_{1.0}$ measurement before

134 and after inhalation of a $\beta$-agonist ( $1 \mathrm{mg}$ Terbutaline) was regarded as positive if $\mathrm{FEV}_{1.0}$

135 increased $\geq 12 \%$ (http://www.ginasthma.com). The $\mathrm{FE}_{\mathrm{NO}}$ was measured at a constant flow of

$13650 \mathrm{~mL} / \mathrm{s}$ with NIOX-MINO (Aerocrine AB, Stockholm, Sweden). The cut off level for a

137 pathological $\mathrm{FE}_{\mathrm{NO}}$ was $20 \mathrm{ppb}$, which is the 95\% percentile in 7-9 year old children [12]. Skin

138 prick tests were done on the volar aspects of the forearm with egg white, fresh skimmed cow

139 milk (lipid concentration 0.5\%) and standardized cat, dog, birch, peanut, mite (Der p) and

140 timothy extracts (Soluprick ${ }^{\circledR}$, ALK, Hørsholm, Denmark). Histamine hydrochloride (10

$141 \mathrm{mg} / \mathrm{ml}$ ) was used as positive and albumin diluent as negative control. The test was regarded as

142 positive if the mean diameter of the wheal was $\geq 3 \mathrm{~mm}$.

144 Diagnostic criteria

145 The child should have had symptoms of and/or have been treated for the actual allergic

146 disease during the last twelve months. Thus, children with allergic disease before school age 
147 who did not have any symptoms during the last twelve months were defined as healthy.

148 Asthma diagnosis required at least one of following two criteria: 1. Doctor diagnosis and

149 asthma symptoms and/or medication during the last twelve months; 2 . Wheeze or nocturnal

150 cough and a positive reversibility test and/or pathological $\mathrm{FE}_{\mathrm{NO}}$ value. In Sweden most

151 children with asthma are asymptomatic when visiting the doctor, since they are efficiently

152 treated with inhaled corticosteroids. If the asthma diagnosis was based on doctors diagnosis,

153 medical records of the child was always reviewed to confirm that the diagnosis were

154 consistent with the GINA criteria (http://www.ginasthma.com). The diagnosis of ARC was

155 based on standard ISAAC question (http://isaac.auckland.ac.nz/Index.html) and required

156 watery discharge at least twice in contact with the same allergen and no signs of infection.

157 Urticaria was defined as allergic when appearing at least twice in conjunction with a certain

158 allergen. Eczema was defined as a pruritic, chronic or chronically relapsing non-infectious

159 dermatitis with typical features and distribution, as suggested by Hanifin and Rajka [13].

160 Eczema was classified as IgE-associated if the infant had also a positive skin prick test.

$16 S$ rDNA sequencing and bioinformatics

163 DNA extraction, 16S rDNA PCR amplification with primer pair 341F-805R targeting V3-V4,

164 PCR product purification, and 454 sequencing were performed as described previously [2].

165 De-noising, chimera removal and complete linkage clustering of sequences into Operational

166 Taxonomic Units (OTUs) were performed with AmpliconNoise [2]. 318,215 high quality,

167 typically 198 bp long, sequence reads remained, with 828 to 12,909 reads per sample (mean $=$

168 2257). These corresponded to 3048 unique sequences and 1856 OTUs, clustered at 97\%

169 similarity level. Taxonomic annotations were conducted by BLAST searching the OTUs

170 against a local BLAST database of $16 \mathrm{~S}$ rDNA sequences from the Ribosomal Database

171 Project (RDP) v. 10.10 [14]. OTUs lacking hits of of $\geq 95 \%$ identity over an alignment of 
172 length $\geq 180 \mathrm{bp}$ were classified as “no_match". If multiple best hits (same score) were found,

173 the taxonomy was set to the most-detailed level of taxonomy shared by the best hits [2].

174

175

176

177

178

179

180

181

182

183

184

185

186

187

188

189

190

191

192

193

194

196

\section{Statistical analyses}

The online version of Fast Unifrac (http://bmf2.colorado.edu/fastunifrac/) [15]was used to calculate weighted sample distances by mapping our OTU sequences with BLAST onto the Greengenes reference sequences (downloaded from the Fast Unifrac web page, May 2009) and using the corresponding Greengenes tree. A Principal Coordinates Analysis (PCoA) plot based on all pair-wise sample distance was created on the Fast Unifrac web page. Our OTU sequences were mapped onto 154 Greengenes sequences. The Shannon diversity index was employed to measure the biodiversity in samples. Briefly, it is a test that takes in account the richness and the evenness of the species, typically with a value between 1.5-3.5 [16]. It was calculated as $-\Sigma \log \left(\mathrm{p}_{i}\right) \mathrm{p}_{i}$, where $\mathrm{p}_{i}$ denotes the frequency of OTU ${ }_{i}$ [17]. Calculations of the index were made with the $R$ software (http://www.r-project.org/) and the $R$ package vegan (http://cran.r-project.org/web/packages/vegan/), and differences in diversity were tested with Mann-Whitney U-test, since the levels were not normally distributed. Evenness was calculated with Pielou's evenness index as $-\Sigma \log \left(\mathrm{p}_{i}\right) \mathrm{p}_{i} / \log \left(S_{o b s}\right)$, where $S_{o b s}$ denotes the number of observed OTUs in the sample. Since these levels are influenced by sequencing depth, and sequencing depth differed between samples, we subsampled (with replacement) 1400 reads from each sample, counted the occurrences of the corresponding OTUs, and performed the diversity calculations on these counts. Only four (out of 141) samples had fewer than 1400 reads and were excluded from this part of the analysis. Statistical significance testing over- and under-representation of the bacterial lineages was made at phylum, class and genus (3\% dissimilarity) levels with Mann-Whitney U-test, and p-values were converted to False Discovery Rate values (q-values) to correct for multiple testing [18]. 
197 The $X^{2}$ test was employed for categorical data, unless the expected frequency for any cell was

198 less than five, when Fisher's exact test was employed. Student's t test were employed for

199 normally distributed continuous data. (SPSS 16.0, SPSS Inc, Chicago, IL, USA). 


\section{Results}

202 At seven years of age, the prevalence of asthma was $17 \%(8 / 47)$, allergic rhinoconjuntivitis $28 \%(13 / 47)$, eczema $26 \%(12 / 47)$, allergic urticaria $9 \%(4 / 47)$, skin prick test reactivity $34 \%$ $(14 / 41)$ and IgE-associated eczema 27\% (11/41). Low total diversity as measured by the

Shannon diversity index of the gut microbiota at one week and one month of age was associated with asthma diagnosis in children at seven years of age (Table 1, Fig. 1a). Allergic rhinoconjunctivitis, SPT reactivity (Table 1), eczema and IgE-associated eczema (Supplementary Table 1) at this age did not associate with the gut microbiota diversity during the first year of life, however. Neither did asthma have any significant association with total microbiota diversity later in infancy (at twelve months) nor any consistent association with

211 the diversity of different bacterial phyla at any age (data not shown). Similar results were 212 obtained when comparing children with asthma, allergic rhinoconjunctivitis, SPT reactivity, eczema and IgE-associated eczema with control children with no allergic manifestations (data not shown). The evenness of the microbial composition according to Pielou's test at one week 215 and one month of age was lower in children with than without asthma (Fig. 1b). Also the 216 number of bacterial OTUs in stool samples tended to be low at one month of age in the 217 asthma group (Table 2). In order to evaluate whether sensitized infants who subsequently 218 developed asthma also had a different gut microbiota composition than sensitized infants who 219 did not, analyses were performed when only the 20 children with IgE-associated eczema at 220 two years of age were included. Indeed, the seven children having IgE-associated eczema in 221 infancy and subsequently developing asthma had a lower microbial diversity than those 13 children who did not (Supplementary Table 2), although the p-values reveal only a trend, probably due to the lost of statistical power $(\mathrm{p}=0.06$ and $\mathrm{p}=0.09$ at one week and one month, 224 respectively). Thus, children with IgE-associated eczema in infancy who had developed 225 asthma at seven years of age had a median of the diversity index of 1.25 (interquartile range; 
0.84-1.45) at one month of age compared to $1.53(1.42-1.72)$ if they did not have asthma and 1.67 (1.51-2.14) if they did not have IgE-associated eczema at two years of age. No such differences were seen for the other allergic manifestations (Supplementary Table 2). Despite the association to asthma, there was no significant correlation between $\mathrm{FE}_{\mathrm{NO}}$ levels and microbial diversity (data now shown). However, the only child with pathological $\mathrm{FE}_{\mathrm{NO}}$ levels ( $>20 \mathrm{ppm}$ ) had very low diversity indices (0.69 at one week and 0.72 at one month).

There were no significant differences in relative abundance of bacterial phyla, classes and genera between children with or without asthma (Table 3) or with and without ARC and eczema (data not shown). Neither did Principal Coordinates Analysis based on Unifrac sample distances reveal any clear separation of samples in relation to asthma (Supplementary Fig. 1) or any other of the allergic diseases (data not shown).

There were no differences regarding potential confounders such as sex, birth order, caesarean section, family history of allergic disease, breastfeeding, furred pets at home, antibiotics, infections and probiotic supplementation between the children with and without asthma (Table 4), nor between children with or without any other allergic manifestation (data not shown). Neither were there any significant associations between these factors and microbial diversity except for exclusive breastfeeding at one month, tending to be associated with low diversity at one month of age ( $\mathrm{p}=0.05$, data not shown). Excluding the seven children who were not breastfed exclusively at one month did not affect the comparison between asthmatic and non-asthmatic infants ( $\mathrm{p}=0.001$, data not shown), however, neither did exclusion of children who were delivered by caesarean section or were supplemented with probiotics, two other factors that might affect the gut microbial diversity at one month $(p=0.009$ after excluding children delivered with caesarean section and $\mathrm{p}=0.03$ after excluding children in the 
251 probiotic group, data not shown). No child received antibiotics during the first month of life.

252 The number of reported infections during the first two years of life did not correlate 253 significantly with total diversity values (data not shown).

254

255 


\section{Discussion}

257 Employing high-throughput 16S rRNA gene based molecular microbiology, we could confirm and extend previous findings, showing that low intestinal diversity during the first month of life is associated with an increased risk of subsequent allergic disease [2, 3, 8-10] and that the effect remains in school age. In contrast to previous studies, however, our results

261 indicate that early gut microbial diversity may be more associated with asthma development 262 at school age than other allergic manifestations. Low gut microbial diversity has previously been associated with IgE-associated eczema at two years of age in the same cohort as the present one [2]. Interestingly, the present study indicates that the low gut microbiota diversity in these infants with IgE-associated eczema at two years of age primarily was confined to 266 children subsequently developing asthma in school age. The absent correlation between the 267 infant gut microbiota and eczema in our study supports the result from a previous study 268 investigating the effect of the microbial diversity on an allergy development until school age 269 [3] and indicates that other factors, e.g. skin barrier dysfunction due to filaggrin mutations, 270 underlie persistent eczema [5]._There was no significant association between asthma and the 271 relative abundance of any phylum or genus, nor any significant sample clustering in asthmatic 272 infants. Thus, the total diversity seems to be more important than any particular microbial 273 group for asthma development, although the lack of significant difference between individual 274 phyla may also be due to low statistical power or in these analyses. Also, stool samples only 275 reflect the microbiota in the luminal space of the colon and not the small intestine and the 276 mucosa. Thus, there might be specific bacterial species important for prevention of asthma as well as ARC, which are not revealed in this study.

279 Previous studies have not revealed any relationship between microbial diversity and asthma 280 development. This is probably primarily due to the fact that most of the clinical follow-ups 
have been performed in young children [2, 8-10], when allergic asthma and

282 rhinoconjunctivitis still are uncommon. It might also be a consequence of methodology

283 limitations. The sensitivity of our analyses was higher than in previous diversity studies [3, 8-

284 10]. In the study by Bisgaard et al. [3], in which infant gut diversity was associated with

285 sensitization but not asthma in school age, the mean of bands/samples, were only 8.5 (with

286 DGGE) at 12 months of age, as compared to 69 OTUs/sample in our study. The community

287 resolution might still not have been high enough in our study to reveal an association between

288 specific bacterial species and asthma and ARC, however. Another important factor possibly

289 affecting the results is the variation of the gut microbiota composition in different countries

290 [19]. Whether our observations in Swedish children can be translated to children in other

291 regions of the world needs to be further investigated.

293 It is noteworthy that the most important differences appeared the first months of life,

294 supporting the theory that factors influencing the early of maturation of the immune system

295 might be especially important for subsequent asthma development [20]. Furthermore, the

296 results indicate that the immunological phenotype preceding asthma development in particular

297 is established during the first month of life. Viral lower respiratory tract infections (LRTIs)

298 have been suggested to be linked to asthma development among atopic children [7]. The

299 incidence of recurrent wheeze, which often are caused by LRTIs in infancy, was $50 \%$ in the

300 infants subsequently developing asthma at 7 years of age compared to $3 \%$ in those that did

301 not. It is tempting to speculate that infants subsequently developing asthma are more prone to

302 getting LRTIs, caused by respiratory syncytial virus or rhinoviruses, because of an attenuated

303 maturation of the immune system as a consequence of low stimulation from the gut

304 microbiota during the first months of life. Also, reduced mucosal barrier function may be

305 linked to high susceptibility of LRTIs, amplification of Th2 responses and subsequent asthma 
development $[7,21]$. Low salivary secretory IgA levels are associated with increased

307 prevalence of late onset wheeze in sensitized infants [22], and interestingly, also low 308 intestinal microbial diversity [23].

The present study does not explain why infants developing asthma have low gut microbial

311 diversity. The differences were not due to antibiotic treatment, which may increase the risk

312 for asthma development [24] as no child received antibiotics during the first month of life.

313 Also, while caesarean section has been linked to asthma development and affects gut

314 microbiota during the first month of life [25], the association between low diversity and

315 asthma remained when including only children born with vaginal delivery. Still, the

316 difference in diversity in neonates may be explained by other factors such as the biodiversity

317 in the homes (mattresses, dust etc.) [26, 27], in the surrounding environment [28] and in

318 family members (skin, mouth and gut) [29]. Also, hygienic practices may influence the

319 microbial diversity and allergy development [30]. Recently, children whose parents "cleaned"

320 their pacifier by sucking it were less likely to have asthma at 18 months of age than children

321 whose parents did not use this cleaning technique [31]. Infants with low gut microbial

322 diversity also had low microbial exposure via the respiratory mucosa. The maturation of the

323 respiratory mucosal immune system depends at least partly on bacterial colonization of the

324 lower airways [32]. Whether asthma, however, would be more related to the nature of

325 microbial colonization of the airways than eczema and allergic rhinoconjunctivitis require

326 further elucidation.

328 In conclusion, low total diversity of the gut microbiota during the first month of life was

329 associated with asthma in children at seven years of age. The early gut microbial diversity

330 seems to be most important for asthma development and did not apply to the other allergic 
Abrahamsson

331 manifestations in school age in our study, although this might be a consequence of the

332 relatively few cases included.

333 


\section{Acknowledgements}

336 We thank Mrs Lena Lindell, Mrs Elisabeth Andersson, Mrs Linnea Andersson and Mrs Eivor

337 Folkesson, Dr Göran Oldaeus and Dr Ted Jacobsson for their brilliant and enthusiastic work

338 guiding the families through the study and all the sampling procedures. We also thank Mrs

339 Anne-Marie Fornander for excellent technical assistance and Christopher Quince for assisting

340 with sequence noise removal.

342 The study was supported by grants from BioGaia AB, Stockholm, Sweden, the Ekhaga

343 Foundation, the Heart and Lung foundation, the Research Council for the South-East Sweden

344 (grant No. F2000-106), The Olle Engqvist Foundation, the Swedish Asthma and Allergy

345 Association, the Swedish Research Council, the University Hospital of Linköping, the

346 Söderberg Foundation, the Vårdal Foundation for Health Care Science and Allergy Research,

347 Sweden. T Abrahamsson, M Jenmalm have received honoraria for lectures and B Björkstén

348 for consulting from Biogaia $\mathrm{AB}$ 


\section{References}

353 1. Holt PG, Björkstén B. Atopic versus infectious diseases in childhood: a question of balance? Pediatr Allergy Immunolol 1997;8:53-8.

2. Abrahamsson TR, Jakobsson HE, Andersson AF, Björkstén B, Engstrand L, Jenmalm MC. Low diversity of the gut microbiota in infants with atopic eczema. J Allergy Clin Immunolol 2012;129:434-40.

3. Bisgaard H, Li N, Bonnelykke K, Chawes BL, Skov T, Paludan-Muller G, Stokholm J, Smith B, Krogfelt KA. Reduced diversity of the intestinal microbiota during infancy is associated with increased risk of allergic disease at school age. J Allergy Clin Immunolol 2011;128:646-52 e5.

4. Adlerberth I, Strachan DP, Matricardi PM, Ahrné S, Orfei L, Åberg N, Perkin MR, Tripodi S, Hesselmar B, Saalman R, Coates AR, Bonanno CL, Panetta V, Wold A. Gut microbiota and development of atopic ezcema in 3 European birth cohorts. $\mathrm{J}$ Allergy Clin Immunolol 2007;120:343-50.

5. Eichenfield LF, Ellis CN, Mancini AJ, Paller AS, Simpson EL. Atopic dermatitis: epidemiology and pathogenesis update. Semin Cutan Med Surg 2012;31:S3-5.

6. Abrahamsson TR, Sandberg Abelius M, Forsberg A, Björkstén B, Jenmalm MC. A Th1/Th2-associated chemokine imbalance during infancy in children developing eczema, wheeze and sensitization. Clin Exp Allergy 2011;41:1729-39.

7. Holt PGSly PD. Viral infections and atopy in asthma pathogenesis: new rationales for asthma prevention and treatment. Nat Med 2012;18:726-35.

8. Wang M, Karlsson C, Olsson C, Adlerberth I, Wold AE, Strachan DP, Martricardi PM, Aberg N, Perkin MR, Tripodi S, Coates AR, Hesselmar B, Saalman R, Molin G, Ahrne S. Reduced diversity in the early fecal microbiota of infants with atopic eczema. J Allergy Clin Immunol 2008;121:129-34.

9. Forno E, Onderdonk AB, McCracken J, Litonjua AA, Laskey D, Delaney ML, Dubois AM, Gold DR, Ryan LM, Weiss ST, Celedon JC. Diversity of the gut microbiota and eczema in early life. Clin Mol Allergy 2008;6:11.

10. Ismail IH, Oppedisano F, Joseph SJ, Boyle RJ, Licciardi PV, Robins-Browne RM, Tang ML. Reduced gut microbial diversity in early life is associated with later development of eczema but not atopy in high-risk infants. Pediatr Allergy Immunolol 2012;23:674-81.

11. Abrahamsson TR, Jakobsson T, Böttcher MF, Fredrikson M, Jenmalm MC, Björkstén B, Oldaeus G. Probiotics in prevention of IgE-associated eczema: a double blind randomised placebo-controlled trial. J Allergy Clin Immunolol 2007;119:1174-80.

12. Buchvald F, Baraldi E, Carraro S, Gaston B, de Jongste J, Pijnenburg MW, Silkoff PE, Bisgaard H. Measurements of exhaled nitric oxide in healthy subjects age 4 to 17 years. J Allergy Clin Immunolol 2005;115:1130-6.

13. Hanifin JMRajka G. Diagnostic features of atopic dermatitis. Acta Dermatol Venereol 1980;(Suppl 92):44-7.

14. Maidak BL, Cole JR, Lilburn TG, Parker CT, Jr., Saxman PR, Stredwick JM, Garrity GM, Li B, Olsen GJ, Pramanik S, Schmidt TM, Tiedje JM. The RDP (Ribosomal Database Project) continues. Nucleic Acids Res 2000;28:173-4.

15. Hamady MKnight R. Microbial community profiling for human microbiome projects: Tools, techniques, and challenges. Genome Res 2009;19:1141-52. 
16. MacDonald GM. Biogeography: Introduction to Space, Time, and Life. John Wiley \& Sons inc 2003.

17. Hayek (1996) Surveying natural populations.

18. Robinson MD, McCarthy DJ, Smyth GK. edgeR: a Bioconductor package for differential expression analysis of digital gene expression data. Bioinformatics 2010;26:139-40.

19. Grzeskowiak L, Grönlund MM, Beckmann C, Salminen S, von Berg A, Isolauri E. The impact of perinatal probiotic intervention on gut microbiota: double-blind placebo-controlled trials in Finland and Germany. Anaerobe 2012;18:7-13.

20. Prescott SL. Early origins of allergic disease: a review of processes and influences during early immune development. Curr Opin Allergy Clin Immunol 2003;3:125-32.

21. Hansel TT, Johnston SL, Openshaw PJ. Microbes and mucosal immune responses in asthma. Lancet 2013;381:861-73.

22. Sandin A, Björksten B, Böttcher MF, Englund E, Jenmalm MC, Bråbäck L. High salivary secretory IgA antibody levels are associated with less late-onset wheezing in IgE-sensitized infants. Pediatr Allergy Immunolol 2011;22:477-81.

23. Sjögren YM, Tomicic S, Lundberg A, Böttcher MF, Björksten B, SverremarkEkström E, Jenmalm MC. Influence of early gut microbiota on the maturation of childhood mucosal and systemic immune responses. Clin Exp Allergy 2009;39:184251.

24. Alm B, Erdes L, Möllborg P, Pettersson R, Norvenius SG, Åberg N, Wennergren G. Neonatal antibiotic treatment is a risk factor for early wheezing. Pediatrics 2008;121:697-702.

25. Kero J, Gissler M, Grönlund MM, Kero P, Koskinen P, Hemminki E, Isolauri E. Mode of delivery and asthma -- is there a connection? Pediatr Res 2002;52:6-11.

26. Ege MJ, Mayer M, Normand AC, Genuneit J, Cookson WO, Braun-Fahrlander C, Heederik D, Piarroux R, von Mutius E. Exposure to environmental microorganisms and childhood asthma. N Engl J Med 2011;364:701-9.

27. Sjögren YM, Jenmalm MC, Böttcher MF, Björkstén B, Sverremark-Ekström E. Altered early infant gut microbiota in children developing allergy up to 5 years of age. Clin Exp Allergy 2009;39:518-26.

28. Hanski I, von Hertzen L, Fyhrquist N, Koskinen K, Torppa K, Laatikainen T, Karisola P, Auvinen P, Paulin L, Makela MJ, Vartiainen E, Kosunen TU, Alenius H, Haahtela T. Environmental biodiversity, human microbiota, and allergy are interrelated. Proc Natl Acad Sci U S A 2012;109:8334-9.

29. Dominguez-Bello MG, Costello EK, Contreras M, Magris M, Hidalgo G, Fierer N, Knight R. Delivery mode shapes the acquisition and structure of the initial microbiota across multiple body habitats in newborns. Proc Natl Acad Sci U S A 2010;107:11971-5.

30. Sherriff AGolding J. Hygiene levels in a contemporary population cohort are associated with wheezing and atopic eczema in preschool infants. Arch Dis Child 2002;87:26-9.

31. Hesselmar B, Sjöberg F, Saalman R, Åberg N, Adlerberth I, Wold AE. Pacifier cleaning practices and risk of allergy development. Pediatrics 2013;131:e1829-37.

32. Renz H, Brandtzaeg P, Hornef $M$. The impact of perinatal immune development on mucosal homeostasis and chronic inflammation. Nat Rev Immunol 2012;12:9-23. 
A
$\ulcorner 0.04\urcorner$
$\lceil 0.003\rceil$

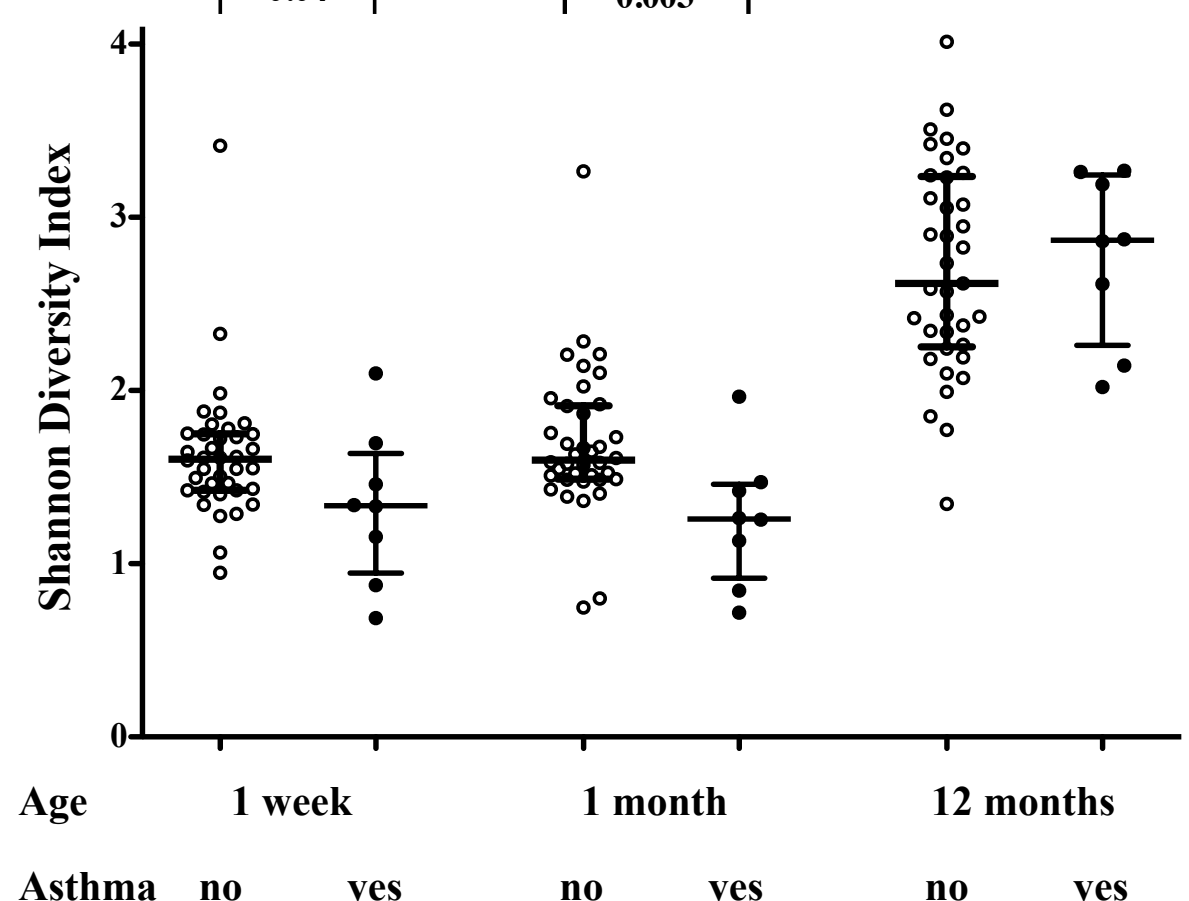

B

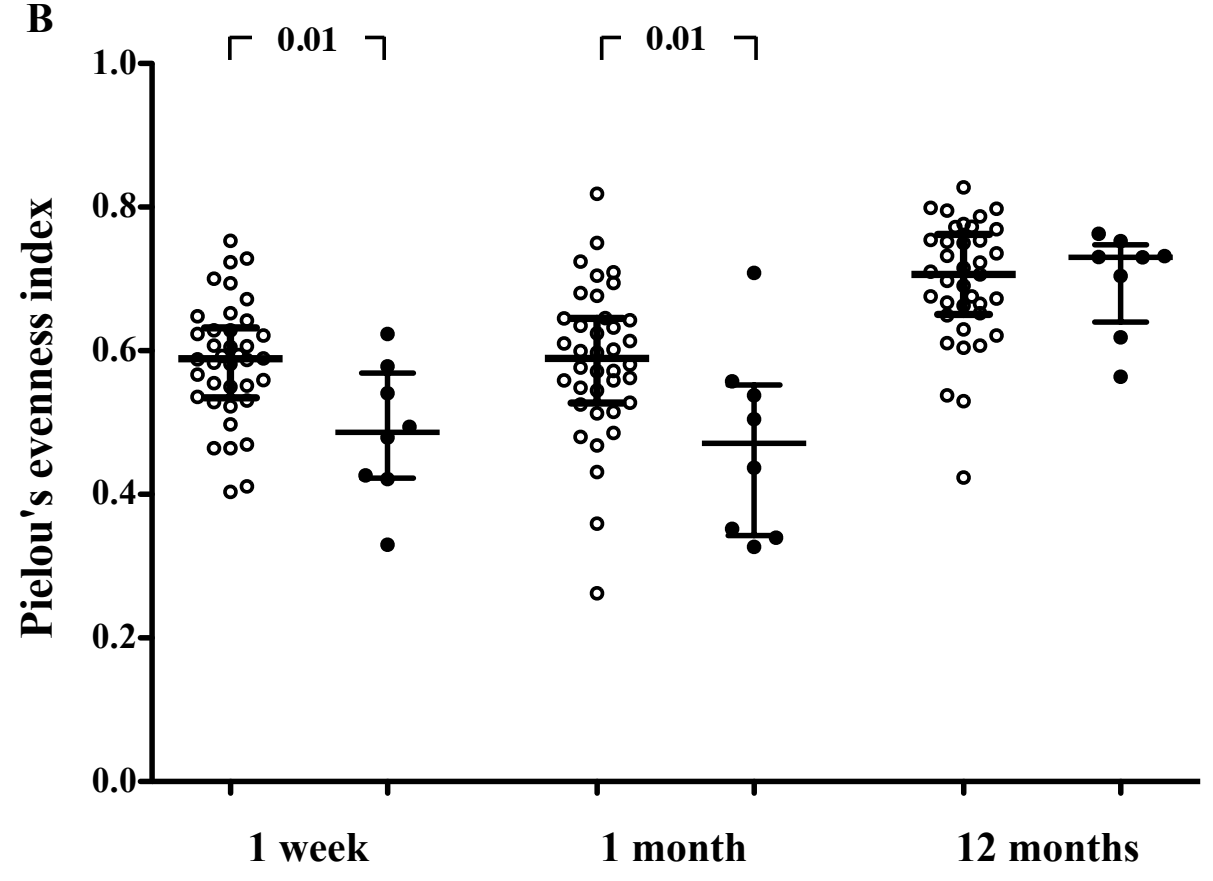

no

yes

no yes

no yes

Fig 1.

The Shannon diversity index (a) and Pielou's evenness index (b) of the gut microbiota in stool samples at one week, one month and twelve months of age in infants with (black circles) and without (clear circles) asthma at seven years of age. The $25^{\text {th }}, 50^{\text {th }}$ and $75^{\text {th }}$ percentiles are indicated. Groups were compared using Mann-Whitney U-test. 
Tables

Table 1. The Shannon diversity index of the total microbiota during the first year of life in children with asthma, allergic rhinoconjunctivitis and positive skin prick test at seven years of age.

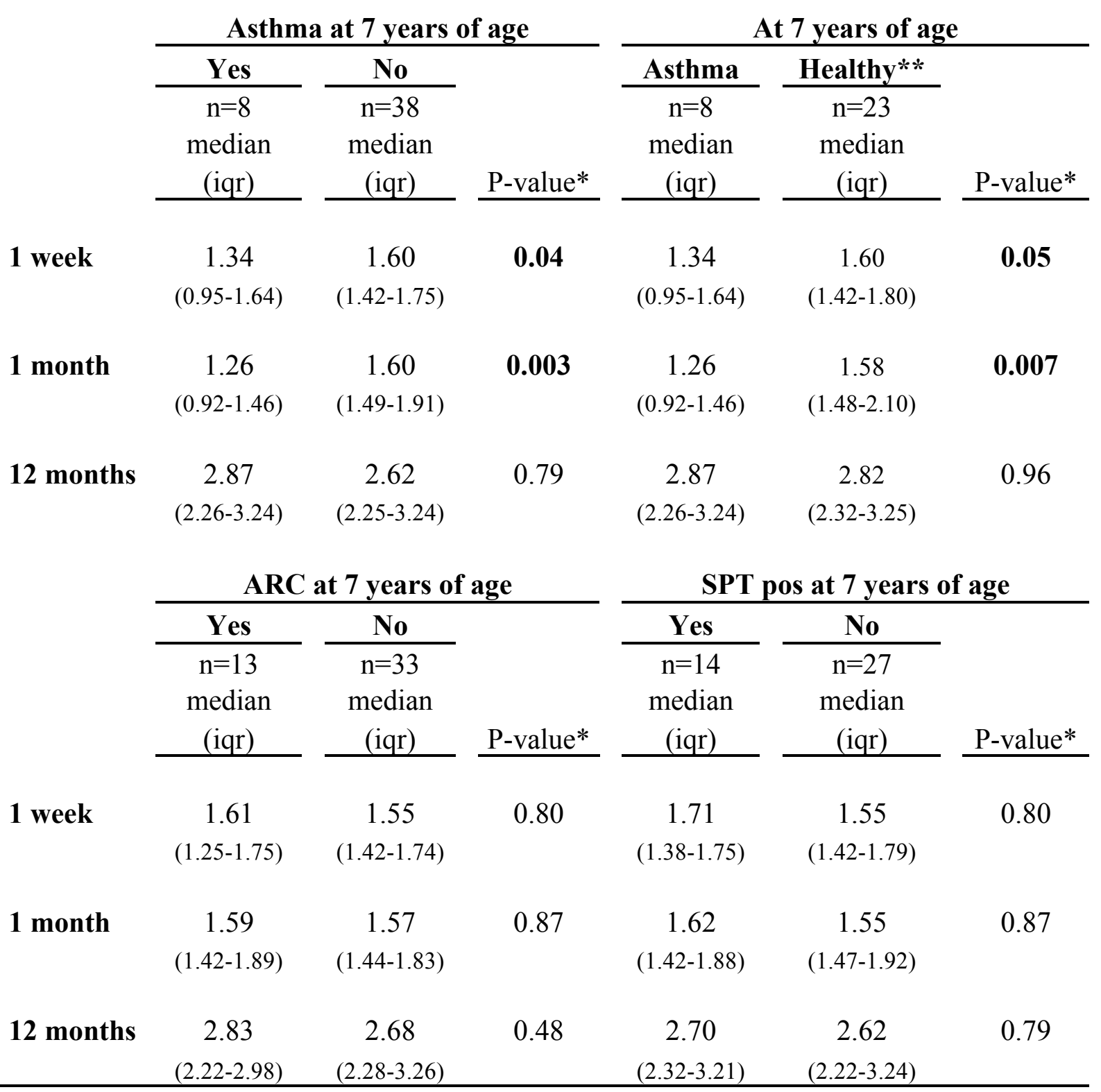

*Mann Whitney U-test. Iqr= interquartile range.

**Healthy $=$ non-sensitised children without any allergic symptoms $0-7 \mathrm{y}$. 
Table 2. The median of all OTUs and taxonomic classified OTUs (bacterial genus)/infant in stool sampl6s during the first year of life in children with and without asthma at seven years of age

\begin{tabular}{|c|c|c|c|c|c|c|}
\hline & \multicolumn{4}{|c|}{ Asthma at 7 years of age } & \multirow{2}{*}{\multicolumn{2}{|c|}{12 months }} \\
\hline & \multicolumn{2}{|c|}{1 week } & \multicolumn{2}{|c|}{1 month } & & \\
\hline & $\begin{array}{c}\text { Yes } \\
n=8 \\
\text { median (iqr) }\end{array}$ & $\begin{array}{c}\text { No } \\
\mathbf{n}=39 \\
\text { median (iqr) }\end{array}$ & $\begin{array}{c}\text { Yes } \\
n=8 \\
\text { median (iqr) }\end{array}$ & $\begin{array}{c}\text { No } \\
\mathbf{n}=39 \\
\text { median (iqr) }\end{array}$ & $\begin{array}{c}\text { Yes } \\
n=8 \\
\text { median (iqr) }\end{array}$ & $\begin{array}{c}\text { No } \\
n=39 \\
\text { median (iqr) }\end{array}$ \\
\hline OTUs & $\begin{array}{c}15 \\
(10-22)\end{array}$ & $\begin{array}{c}16 \\
(13-18)\end{array}$ & $\begin{array}{c}14 \# \\
(12-17)\end{array}$ & $\begin{array}{c}18 \# \\
(14-22)\end{array}$ & $\begin{array}{c}51 \\
(40-73)\end{array}$ & $\begin{array}{c}47 \\
(33-59)\end{array}$ \\
\hline Classified OTUs & $\begin{array}{c}15 \\
(8-22)\end{array}$ & $\begin{array}{c}15 \\
(12-18)\end{array}$ & $\begin{array}{c}14 \\
(12-15)\end{array}$ & $\begin{array}{c}17 \\
(14-21)\end{array}$ & $\begin{array}{c}50 \\
(39-71)\end{array}$ & $\begin{array}{c}47 \\
(33-59)\end{array}$ \\
\hline $\begin{array}{c}\text { Classified OTUs } \\
\text { to genus level }\end{array}$ & $\begin{array}{c}13 \\
(6-19)\end{array}$ & $\begin{array}{c}12 \\
(10-15)\end{array}$ & $\begin{array}{c}11^{*} \\
(10-12)\end{array}$ & $\begin{array}{c}14 * \\
(11-17)\end{array}$ & $\begin{array}{c}39 \\
(30-46)\end{array}$ & $\begin{array}{c}33 \\
(22-45)\end{array}$ \\
\hline
\end{tabular}

iqr=interquartile range. $\# \mathrm{p}=0.09,{ }^{*} \mathrm{p}=0.06$ with Mann Whitney U-test. 
Table 3. The mean of the relative abundance of dominant phyla (bold), classes and genera (relative abundance $>1 \%$ at any age) in stool samples obtained at various ages from infants who did or did not develop asthma at seven years of life.

\begin{tabular}{|c|c|c|c|c|c|c|}
\hline & \multicolumn{2}{|c|}{ Asthma 1 week } & \multicolumn{2}{|c|}{ Asthma 1 month } & \multicolumn{2}{|c|}{ Asthma 12 months } \\
\hline & Yes & No & Yes & No & Yes & No \\
\hline & $\begin{array}{c}\mathrm{n}=8 \\
\text { mean \% } \\
(\mathrm{SD})\end{array}$ & $\begin{array}{c}\mathrm{n}=39 \\
\text { mean \% } \\
(\mathrm{SD})\end{array}$ & $\begin{array}{c}\mathrm{n}=8 \\
\text { mean \% } \\
(\mathrm{SD})\end{array}$ & $\begin{array}{c}\mathrm{n}=39 \\
\text { mean \% } \\
(\mathrm{SD})\end{array}$ & $\begin{array}{c}\mathrm{n}=8 \\
\text { mean \% } \\
(\mathrm{SD})\end{array}$ & $\begin{array}{c}\mathrm{n}=39 \\
\text { mean \% } \\
(\mathrm{SD})\end{array}$ \\
\hline Actinobacteria & $26(32)$ & $23(24)$ & $48(36)$ & $34(27)$ & $5(5)$ & $14(17)$ \\
\hline Bifidobacterium & $25(33)$ & $22(24)$ & $47(35)$ & $32(27)$ & $4(5)$ & $13(17)$ \\
\hline Collinsella & $<1$ & $<1$ & $<1$ & $1(2)$ & $<1$ & $<1$ \\
\hline Proteobacteria & $18(22)$ & $19(18)$ & $12(12)$ & $13(13)$ & $5(9)$ & $17(21)$ \\
\hline $\begin{array}{l}\text { Enterobacteriaceae } \\
\text { (unclassified) }\end{array}$ & $18(22)$ & $11(17)$ & $11(13)$ & $6(11)$ & $<1$ & $2(4)$ \\
\hline Bacteriodetes & $7(20)$ & $14(22)$ & $5(9)$ & $17(21)$ & $12(12)$ & $10(11)$ \\
\hline Bacteroides & 7 (19) & $12(19)$ & $5(9)$ & $14(20)$ & $8(10)$ & $9(11)$ \\
\hline Parabacteroides & $<1$ & $2(5)$ & $<1$ & $1(4)$ & $<1$ & $<1$ \\
\hline Prevotella & $<1$ & $<1$ & $<1$ & $<1$ & $3(8)$ & $<1$ \\
\hline Firmicutes & $49(36)$ & $44(28)$ & $34(36)$ & $36(25)$ & $80(15)$ & $70(18)$ \\
\hline Bacilli class & $33(29)$ & $29(24)$ & $7(4)$ & $15(13)$ & $2(4)$ & $7(12)$ \\
\hline Streptococcus & $4(5)$ & $15(16)$ & $4(4)$ & $10(12)$ & $2(3)$ & $4(7)$ \\
\hline Enterococcus & $18(21)$ & $6(13)$ & $1(2)$ & $3(6)$ & $<1$ & $2(10)$ \\
\hline Lactobacillus & $<1$ & $1(3)$ & $1(2)$ & $1(3)$ & $<1$ & $<1$ \\
\hline Staphylococus & $10(12)$ & $7(9)$ & $1(2)$ & $1(2)$ & $<1$ & $<1$ \\
\hline Clostridia class & $15(19)$ & $14(14)$ & $27(35)$ & $18(21)$ & $71(12)$ & $58(20)$ \\
\hline $\begin{array}{l}\text { Veillonella } \\
\text { Lachnospiraceae }\end{array}$ & $3(4)$ & $5(8)$ & $1(1)$ & $2(4)$ & $2(3)$ & $2(2)$ \\
\hline Incertae Sedis & $3(9)$ & $<1$ & $2(5)$ & $2(6)$ & $7(5)$ & $5(5)$ \\
\hline Peptostreptococcaceae & & & & & & \\
\hline Incertae Sedis & $<1$ & $1(3)$ & $<1$ & $1(2)$ & $4(4)$ & $4(4)$ \\
\hline Erysipelotrichaceae & & & & & & \\
\hline Incertae Sedis & $<1$ & $<1$ & $<1$ & $2(7)$ & $3(3)$ & $4(5)$ \\
\hline Clostridium & $<1$ & $1(3)$ & $5(9)$ & $1(6)$ & $<1$ & $1(3)$ \\
\hline Faecalibacterium & $<1$ & $<1$ & $<1$ & $<1$ & $2(3)$ & $3(4)$ \\
\hline Ruminococcus & $<1$ & $<1$ & $<1$ & $<1$ & $1(1)$ & $2(3)$ \\
\hline Anaerostipes & $<1$ & $<1$ & $<1$ & $<1$ & $4(6)$ & $1(1)$ \\
\hline $\begin{array}{l}\text { Anaerococcus } \\
\text { (Unclassified) }\end{array}$ & $<1$ & $<1$ & $<1$ & $1(6)$ & $<1$ & $<1$ \\
\hline $\begin{array}{l}\text { Lachnospiraceae } \\
\text { (Unclassified) }\end{array}$ & $<1$ & $<1$ & $<1$ & $<1$ & $8(8)$ & $6(6)$ \\
\hline $\begin{array}{l}\text { Erysipelotrichaceae } \\
\text { (Unclassified) }\end{array}$ & $<1$ & $<1$ & $<1$ & $<1$ & $3(5)$ & $<1$ \\
\hline Ruminococcaceae & $<1$ & $<1$ & $<1$ & $<1$ & $1(1)$ & $1(1)$ \\
\hline Verrucomicrobia & $<1$ & $<1$ & $<1$ & $1(4)$ & $2(4)$ & $2(5)$ \\
\hline Akkermansia & $<1$ & $<1$ & $<1$ & $1(4)$ & $2(4)$ & $2(5)$ \\
\hline
\end{tabular}


Table 4. The background factors and other allergic manifestations in children with and without asthma at seven years of age

\begin{tabular}{|c|c|c|c|}
\hline & \multicolumn{2}{|c|}{ Asthma at 7 years of age } & \multirow[b]{3}{*}{$\mathrm{P} *$} \\
\hline & Yes & No & \\
\hline & $\%(n / N)$ & $\%(n / N)$ & \\
\hline Probiotic group & $25(2 / 8)$ & $38(15 / 39)$ & 0.69 \\
\hline Boys & $88(7 / 8)$ & $51(20 / 39)$ & 0.11 \\
\hline Older sibling & $38(3 / 8)$ & $51(20 / 39)$ & 0.70 \\
\hline Maternal atopy & $88(7 / 8)$ & $87(34 / 39)$ & 1.00 \\
\hline Asthma in family & $75(6 / 8)$ & $46(18 / 49)$ & 0.25 \\
\hline Ceasarean section & $13(1 / 8)$ & $23(9 / 39)$ & 0.68 \\
\hline Breastfeeding (exclusive) at $1 \mathrm{~m}$ & $88(7 / 8)$ & $85(33 / 39)$ & 1.00 \\
\hline Breastfeeding (any) at $1 \mathrm{~m}$ & $100(8 / 8)$ & $100(39 / 39)$ & 1.00 \\
\hline Breastfeeding (any) at $12 \mathrm{~m}$ & $13(1 / 8)$ & $38(15 / 39)$ & 0.23 \\
\hline Furred pets at birth & $0(0 / 8)$ & $8(3 / 39)$ & 1.00 \\
\hline Antibiotics 0-12 m & $25(2 / 8)$ & $21(8 / 39)$ & 1.00 \\
\hline Infections 0-12m mean (sd) & $5.3(3.4)$ & $5.6(2.6)$ & 0.71 \\
\hline Infections 12-24m mean (sd) & $6.1(2.9)$ & $5.3(4.0)$ & 0.57 \\
\hline Day-care at 12 months of age & $0(0 / 8)$ & $5(2 / 39)$ & 1.00 \\
\hline Day-care at 24 months of age & $88(7 / 8)$ & $77(30 / 39)$ & 0.67 \\
\hline Parental smoking (prebirth) & $0(0 / 8)$ & $15(6 / 39)$ & 0.57 \\
\hline Parental smoking at $7 \mathrm{y}$ & $0(0 / 8)$ & $13(5 / 39)$ & 0.57 \\
\hline Probiotics at 7 y (last month) & $0(0 / 8)$ & $28(11 / 39)$ & 0.17 \\
\hline Family size at 7 y mean (sd) & $4.3(0.71)$ & $4.3(0.76)$ & 0.82 \\
\hline Recurrent wheeze $(\geq 3)$ at $2 y$ & $50(4 / 4)$ & $3(1 / 39)$ & 0.002 \\
\hline IgE-associated eczema 2 y & $88(7 / 8)$ & $37(13 / 35)$ & 0.02 \\
\hline Skin prick positive at $7 \mathrm{y}$ & $60(3 / 5)$ & $31(11 / 36)$ & 0.32 \\
\hline Allergic rhinoconjunctivitis at $7 \mathrm{y}$ & $50(4 / 8)$ & $23(9 / 39)$ & 0.19 \\
\hline Allergic urticaria at $7 \mathrm{y}$ & $13(1 / 8)$ & $8(3 / 39)$ & 0.54 \\
\hline Eczema at 7 y & $38(3 / 8)$ & $23(9 / 39)$ & 0.40 \\
\hline
\end{tabular}

Asthma at 7 years of age

* Chi2 test was employed for cathegorical variable. Fisher's exact test was used when the expected frequency for any cell was less than five. Student t-test was employed for continuous variables. 
Supplementary Table 1. The Shannon diversity index of the total microbiota during the first year of life in children with and without eczema and IgE-associated eczema at seven years of age.

\begin{tabular}{ccc}
\multicolumn{2}{c}{ Eczema at 7 years of } \\
\cline { 1 - 1 } Yes & No \\
$=12$ & & $\mathrm{n}=34$ \\
median & & median \\
(iqr) & (iqr) \\
\hline
\end{tabular}

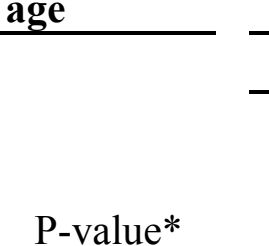

\section{IgE-associated eczema at 7 years of age}

\begin{tabular}{|c|c|c|}
\hline Yes & No & \\
\hline $\mathrm{n}=11$ & $\mathrm{n}=30$ & \\
\hline $\begin{array}{c}\text { median } \\
\text { (igr) }\end{array}$ & $\begin{array}{c}\text { median } \\
\text { (iqr) }\end{array}$ & P-value* \\
\hline
\end{tabular}

\section{1 week}

$$
1.65
$$

1.55

$(1.36-1.75)$

$$
(1.40-1.74)
$$

0.58

$$
1.70
$$$$
1.55
$$

1 month

$$
\begin{array}{cc}
1.54 & 1.57 \\
(1.41-1.66) & (1.46-1.92)
\end{array}
$$

0.48

(1.34-1.75)

(1.43-1.79)

$$
\begin{gathered}
1.49 \\
(1.40-1.63)
\end{gathered}
$$

1.58

(1.48-1.92)

12 months

$\begin{array}{cc}2.84 & 2.62 \\ (2.37-3.16) & (2.17-3.25)\end{array}$

0.68

$$
2.83
$$

2.62

0.73

*Mann Whitney U-test. Iqr= interquartile range

$(2.21-3.24)$ 
Supplementary Table 2. The Shannon diversity index of the total microbiota during the first year of life in children with asthma, allergic rhinoconjunctivitis, eczema and positive skin prick test at seven years of age, when only the 20 children with IgEassociated eczema at two years were included

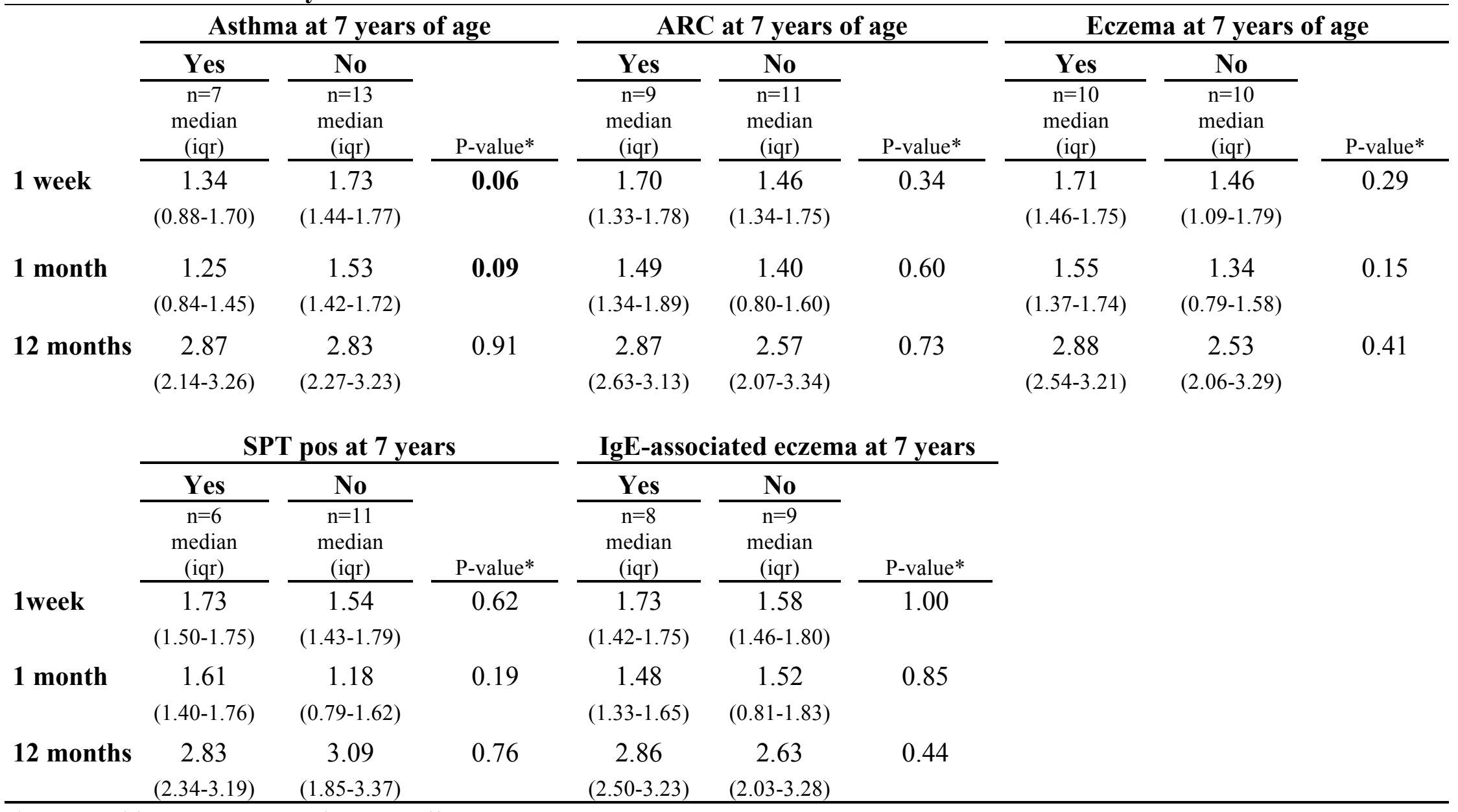

*Mann Whitney U-test. Iqr=interquartile range 